Article

\title{
Oxidized Low-Density Lipoprotein Serum Concentrations and Cardiovascular Morbidity in End Stage of Renal Disease ${ }^{t}$
}

\author{
Vaia Raikou ${ }^{1, *(0)}$, Vasilios Kardalinos ${ }^{2}$ and Despina Kyriaki ${ }^{3}$ \\ Department of Nephrology, DOCTORS' Hospital, 26 Kefallinias, Athens 11257, Greece \\ Department of Cardiology, DOCTORS' Hospital, Athens 11257, Greece; Wolfbad@otenet.gr \\ Department of Nuclear Medicine, General Hospital “LAÏKO”, Athens 11527, Greece; dkyriaki@gmail.com \\ * Correspondence: vraikou@med.uoa.gr; Tel.: +30-21-0821-2000; Fax: +30-21-0821-8228 \\ + Running title: ox-LDL and cardiovascular disease in hemodialysis
}

Received: 21 May 2018; Accepted: 20 June 2018; Published: 21 June 2018

\begin{abstract}
Introduction: Oxidized low-density lipoprotein (ox-LDL) is considered a main biomarker of oxidative stress, a common characteristic in end stage renal disease. We examined the relationship between ox-LDL serum concentrations and cardiovascular disease in permanent hemodiafiltration therapy patients. Methods: Ox-LDL values were measured by ELISA and were corrected for LDL-cholesterol (LDL-C) in 96 participants and in 45 healthy control subjects. We performed chi-square tests and adjusted models for the role of ox-LDL on cardiovascular morbidity including coronary artery disease, left ventricular hypertrophy, systolic, diastolic dysfunction and peripheral arterial disease. Results: ox-LDL/LDL-C values were significantly higher in patients than in control group $(p=0.02)$, due to increased ox-LDL serum levels rather than to low LDL-C. The unadjusted relationship between high ox-LDL/LDL-C and low ejection fraction was found significant $\left(x^{2}=9.04, p=0.003\right)$, although the association with the other cardiovascular manifestations was found non-significant. In the adjusted model for the prediction of systolic cardiac dysfunction, high ox-LDL/LDL-C, old age and non-administration of vitamin D supplementation during dialysis session were found to be significant predictors after adjustment to the confounder. Moreover, the association between systolic cardiac dysfunction and non-administration of vitamin $\mathrm{D}$ derivatives during dialysis sessions was found significant $\left(x^{2}=6.9, p=0.008\right)$. Conclusions: This study showed a significant association between high ox-LDL and systolic cardiac dysfunction in permanent hemodiafiltration therapy patients. This relationship seems to be influenced by aging and pharmaceutical therapy during dialysis sessions, including vitamin D derivatives.
\end{abstract}

Keywords: lipoprotein oxidation; oxidative stress; hemodiafiltration; cardiovascular disease; malnutrition; vitamin D

\section{Introduction}

Renal disease results in accelerated atherosclerosis and increased morbidity and mortality, mainly for cardiovascular causes due either to uremia-related risk factors, such as anemia, hyperparathyroidism, inflammation, oxidative stress and malnutrition [1], or to traditional ones, such as age, male gender, diabetes, obesity, hypertension, smoking, and dyslipidemia [2]. In spite of the initiation of renal replacement therapy, the mortality remains high, above $20 \%$ per year, with more than one half of the deaths being related to cardiovascular disease [3].

Cardiovascular disease is mainly characterized by vascular occlusive disease defined by myocardial infarction and cerebrovascular strokes. The underlying disease progresses through 
various mechanisms, including left ventricular hypertrophy, plaque formation, arterial stiffening and endothelial dysfunction [4]. However, heart failure and sudden death are more common in these patients than atherosclerotic events.

Oxidative stress plays a significant role in the pathogenesis of cardiovascular disease, including heart failure (HF) [5]. Several plasma biochemical markers of oxidative stress were found increased in HF subjects, including oxidized low-density lipoprotein (ox-LDL) levels. Ox-LDL was suggested to play a key role in atherosclerosis development and increased plasma levels of ox-LDL were considered to be a prognostic indicator of mortality in the general population with congestive HF [6].

End-stage renal disease results in atherogenic diathesis, which is mainly associated with oxidative stress and inflammation [7]. Lipid abnormalities, including lipid oxidation, related to a dysfunctional high-density lipoprotein (HDL) may provide a role in clinical outcomes of patients in hemodialysis therapy [8].

In this study, we considered the relationship between ox-LDL serum concentrations and the development of cardiovascular disease in patients attending for permanent outpatient hemodiafiltration therapy. The preliminary hypothesis-driven for this study was based on the research regarding significant risk factors for cardiovascular morbidity and mortality in these patients.

\section{Methods}

\subsection{Patients}

This is a dual-center, retrospective and cross-sectional study of a cohort of 96 patients. The study was approved by the "Laiko, University General Hospital of Athens" and Renal Unit of "Diagnostic and Therapeutic Center of Athens Hygeia SA" Institutional Review Board. All participants provided informed oral consent prior to study enrollment.

All procedures were in accordance with the ethical standards of the institutional and/or national research committee and with the 1964 Helsinki declaration and its later amendments or comparable ethical standards.

62 males and 34 females were included in this study, on mean age $62.1 \pm 14.3$ years old. The median time in hemodiafiltration treatment was 5 years \pm interquartile range 2.1-9.

Patients $<18$ years of age at initiation of dialysis and patients who had less than 6 months of follow-up were excluded from our study. We also excluded patients with autoimmune diseases, malignancy, infections, subjects without regular vascular hemodialysis access and the patients with interdialytic weight gain of more than $5 \%$ of total body weight. Other exclusion criteria included multiple intradialytic hypotensive episodes, cerebrovascular disease, atrial fibrillation and the need to change blood pressure medications.

Participating subjects were attending for outpatient on-line-pre-dilution hemodiafiltration (on-lHDF) therapy, which was prescribed for 3-times weekly with a dialysis time of $4 \mathrm{~h}$ per session, a filter of $1.5 \mathrm{~m}^{2}$ surface area by the high-flux same material synthetic membrane, defined by an ultra-filtration coefficient $>20 \mathrm{~mL} / \mathrm{h}$ [9], using the same volume of replacement liquid, equal to $20 \mathrm{~L}$, and a blood flow of $400 \mathrm{~mL} / \mathrm{min}$. We also used the same sodium concentration, equal to $140 \mathrm{mmol} / \mathrm{L}$, during dialysis sessions. A bicarbonate-based ultrapure buffer dialysis solution was used with a dialysate flow rate of 500-600 $\mathrm{mL} / \mathrm{min}$, a calcium concentration of $1.50-1.75 \mathrm{mmol} / \mathrm{L}$ and low molecular weight heparin as anticoagulant therapy. The final concentration of bicarbonate in dialysate was $32 \mathrm{mmol} / \mathrm{L}$. Dialysis sufficiency was defined by spKt/V/day (single pool, $\mathrm{K}$, dialyzer clearance; $\mathrm{t}$, time; V, urea distribution volume), which was calculated according to the formula of Daugirdas [10]. Patients were excluded if they had a spKt/V of less than 1.2.

The included patients were in a good status and they did not have interdialytic peripheral edema, interdialytic orthostatic hypotension or other characteristics of an inaccurate dry body weight.

The patients with pre-dialysis blood pressure $\geq 140 / 90 \mathrm{mmHg}(n=40$, a prevalence of $41.7 \%)$ were considered hypertensive, and each of them received anti-hypertensive medications, including calcium 
channel blockers, beta-blockers or inhibitors of angiotensin II receptors. Twenty-one of the studied patients were current smokers (a prevalence of $21.9 \%$ ), but none of them had alcohol intake. Thirty-five of the enrolled patients (36.5\%) preserved a residual renal function (RRF) with an interdialytic urine volume of more than $100 \mathrm{~mL}$.

Cardiovascular morbidity was defined as the presence of left ventricular hypertrophy (LVH, $n=54,56.3 \%)$, coronary artery disease (CAD, $n=30,31.3 \%)$, congestive heart failure (CHF) and peripheral arterial disease ( $\mathrm{PAD}, n=39,40.6 \%$ ). The coronary syndrome was documented by history of myocardial infarction, coronary artery angioplasty or bypass surgery, or clinical signs of angina pectoris. The congestive heart failure was defined by systolic dysfunction $(n=26,27.1 \%)$ or by the presence of diastolic dysfunction $(n=67,69.8 \%)$. The systolic function of the left ventricle (LV) was assessed by the measurement of ejection fraction (EF) and systolic dysfunction was defined as $\mathrm{EF}<50 \%$. The diastolic function of LV was assessed by determination of the maximum velocity of the early (E) and late (A) phase of ventricular filling and the calculation of the E/A ratio (ratio of early-to-late trans-mitral flow velocity). The diastolic dysfunction of $\mathrm{LV}$ was defined as $\mathrm{E} / \mathrm{A} \leq 1$.

Peripheral arterial disease was documented by both measurement of ankle-brachial blood pressure index (ABI) and a set of clinical criteria including cool skin, reduced or lost ankle pulse on physical examination, symptomatic intermittent claudication, and by a history of past ischemic amputation or limb artery revascularization. The first and the current cardiovascular events during the study were recorded as one event for the studied cardiovascular manifestations.

Calcium-free phosphate binders were prescribed. None of the enrolled patients was receiving statin or $\mathrm{NaHCO}_{3}$ per os. Forty-seven of our subjects (a ratio of $49 \%$ ) were being treated by intravenous administration of vitamin D supplementation by using calcitriol or paricalcitol during dialysis session, depending mainly on serum calcium and phosphate levels. None of the enrolled patients had received intravenous administration of iron during the last 2 months before the start of the study. The total of enrolled subjects was treated with erythropoietin- $\alpha$ or- $\beta$ agent in combination to orally receiving trivalent iron (ferric hydroxide polymaltose complex).

In our data, renal failure was caused by hypertensive nephrosclerosis at a ratio of $32.3 \%$, chronic glomerulonephritis at a ratio of $28.1 \%$, polycystic disease at a ratio $12.5 \%$, diabetic nephropathy at a ratio equal to $11.5 \%$ and other causes at a ratio $15.6 \%$.

\subsection{Blood Collection}

Blood was drawn at the same time point for each subject included in the study, just before the start of the mean weekly dialysis session in a $12 \mathrm{~h}$ fasting state from the vascular access. The received samples were centrifuged and the fresh serum was used for the biochemical measurements of the study. Serum was also conserved and processed for various assays.

\subsection{Laboratory Measurements}

Albumin, glucose, calcium (Ca) corrected for the albumin levels, phosphate (P), cholesterol, triglycerides, low density lipoproteins (LDL) and high-density lipoproteins (HDL) were measured using spectrophotometric technique by Chemistry Analyzer (MINDRAY BS-200, Diamond Diagnostics, Holliston, MA, USA). The LDL/HDL ratio and the $\mathrm{Ca} \times \mathrm{P}$ products were calculated. Hematological analyzer (Sysmex, xt-4000i, Roche, Wiesbaden, Germany) was used for hemoglobin.

Oxidized LDL (ox-LDL) serum concentrations were measured using enzyme linked immunoabsorbed assay (ELISA), Immundiagnostik AG., Stubenwald-Allee (Bensheim, Germany), in accordance to manufacturer's specification. OxLDL values were measured in the enrolled subjects and in 45 healthy subjects, who were matched for age, gender and BMI with the group of patients. The ratio of ox-LDL/LDL-C was calculated. High-sensitivity C-reactive protein (hsCRP), monocyte chemoattractant protein-1 (MCP-1) and tumor necrosis factor-a (TNF-a) serum concentrations were also measured using ELISA, Immundiagnostik AG., Bensheim, Germany, Alpco Diagnostics, Anachem, Salem, NH, USA and Ani Biotech Oy, Orgenium, Helsinki, Finland, respectively, according to the 
specifications of the manufacturers. The concentrations of intact-parathormone (i-PTH) and insulin were measured by radioimmunoassays (CIS bio international, Saclay, France and BioSource Europe SA, Nivelles, Belgium, respectively). Insulin resistance was calculated using the homeostasis model assessment of insulin resistance (HOMA-IR) [11].

Normalized protein catabolic rate for dry body mass (nPCR) was calculated from the urea generation rate [12]. Body mass index (BMI) was obtained from height and post-dialysis body weight.

\subsection{Hemodynamic and Echo-Cardiographical Measurements}

The mean of 12 measurements of pre-dialysis peripheral systolic and diastolic blood pressures (SBP and DBP respectively) was recorded during a treatment month using an automatic sphygmomanometer OMRON M4-I (Co Ltd. Kyoto, Japan). Mean peripheral pre-dialysis BP (MBP) was calculated as: $\mathrm{MBP}=\mathrm{DBP}+1 / 3(\mathrm{SBP}-\mathrm{DBP})$.

Hemodynamic and echo-cardiographical measurements were also performed before the mid-week dialysis session in combination with blood tests after resting of the patients for at least $10 \mathrm{~min}$. Arterial stiffness was measured as carotid-femoral pulse wave velocity (c-f PWV) and carotid augmentation index (Aix) using the SphygmoCor system ${ }^{\circledR}$ (AtCor Medical Pty. Ltd., Sydney, Australia) according to manufacturer's specifications. In each subject, two sequences of measurements were performed, and the mean value was used for statistical analysis. Pulse pressure (PP) was derived. Ankle-brachial blood pressure index (ABI) was also calculated as the ratio of the lower values of ankle systolic pressure (pre or post-tibial artery), divided by stabilized arm systolic pressure. ABI values less than 0.9 were rated as low indicating peripheral arterial disease (PAD) and values more than 1.4 were rated as high.

Echo-cardiographical assessment was conducted by a Hewlett Packard SONOS 2500 device using a 2.25 MHz transducer (Med-Electronics, Beltsville, MD 20705, USA). All subjects were examined with the method of conventional M-mode and two-dimensional echocardiography by two cardiologists for the estimation of the hypertrophy of LV, systolic and diastolic dysfunction and of the ischemic findings according to the recommendations of the American Society of Echocardiography [4]. The left ventricular hypertrophy was defined by an inter-ventricular septum thickness more than $11.5 \mathrm{~mm}$.

\subsection{Data Analysis}

Data were analyzed using SPSS 15.0 statistical package for Windows (SPSS Inc., Chicago, IL, USA) and expressed as mean \pm standard deviation or as median value ( \pm inter-quartile range) for data that showed skewed distribution. Differences between mean values were assessed by using unpaired $t$-test for two groups and data that showed skewed distributions were compared with Mann-Whitney $U$-test. Correlations between variables were defined by Spearman coefficient and the relationships between categorical variables were defined by chi-square tests. $p$ values less than 0.05 were considered significant. ROC curve analysis was used for the determination of ox-LDL cut off point related to systolic cardiac dysfunction. We built models by using logistic regression analysis examining the role of ox-LDL on cardiovascular disease manifestations adjusting for traditional and specific covariates for hemodialysis patients.

\section{Results}

We corrected the measured by ELISA ox-LDL serum concentration for serum LDL-C with the calculation of the ratio ox-LDL/LDL-C.

In Table 1, the differences between patients and healthy control subjects are shown. We did note that ox-LDL/LDL-C significantly differed between patients and control group, due mainly to a significantly higher ox-LDL in combination with lower LDL-C in the group of patients in comparison to healthy control subjects. 
Table 1. Differences between hemodiafiltration patients $(n=96)$ and healthy control subjects $(n=45)$ $(* p<0.05)$.

\begin{tabular}{|c|c|c|c|}
\hline Characteristic & $\begin{array}{c}\text { Hemodiafiltration Patients }(n=96) \\
\text { Mean } \pm \text { SD or/Mean Rank }\end{array}$ & $\begin{array}{l}\text { Healthy Control Subjects }(n=45) \\
\text { Mean } \pm \text { SD or/Mean Rank }\end{array}$ & $p$ Value \\
\hline Gender (males \%/females \%) & $62(64.6 \%) / 34(35.4 \%)$ & $24(53.3 \%) / 21(46.7 \%)$ & 0.1 \\
\hline Age (years) & $62.1 \pm 14.2$ & $59.6 \pm 11.9$ & 0.6 \\
\hline BMI $\left(\mathrm{Kg} / \mathrm{m}^{2}\right)$ & $25.08 \pm 3.9$ & $25.9 \pm 3.6$ & 0.2 \\
\hline Cholesterol (mg/dL) & $163.4 \pm 45.3 *$ & $188.7 \pm 27.3$ & 0.001 \\
\hline LDL $(\mathrm{mg} / \mathrm{dL})$ & $90.5 \pm 37.2$ & $99.08 \pm 29.6$ & 0.8 \\
\hline HDL (mg/dL) & $38.9 \pm 9.7 *$ & $53.9 \pm 8.9$ & 0.001 \\
\hline Triglycerides (mg/dL) & $172.1 \pm 87.1 *$ & $86.8 \pm 35.6$ & 0.001 \\
\hline oxLDL $(\mathrm{ng} / \mathrm{mL})$ & $69.4 *$ & 54.4 & 0.03 \\
\hline OxLDL/LDL (ng/mg) & $76.2 *$ & 59.8 & 0.02 \\
\hline Glucose (mg/dL) & $96.2 \pm 22.2 *$ & $89.06 \pm 9.6$ & 0.009 \\
\hline Insulin $(\mu \mathrm{U} / \mathrm{mL})$ & $78.6 *$ & 50.8 & 0.001 \\
\hline HOMA-IR (mmol/L) & $79.9 *$ & 52.02 & 0.001 \\
\hline $\mathrm{hsCRP}(\mathrm{mg} / \mathrm{L})$ & $8.6 \pm 5.9^{*}$ & $2.8 \pm 2.3$ & 0.001 \\
\hline $\mathrm{MCP}-1$ (pg/mL) & 69.8 & 68.6 & 0.9 \\
\hline $\mathrm{TNF}-\alpha(\mathrm{pg} / \mathrm{mL})$ & $83.6 *$ & 65.08 & 0.01 \\
\hline i-PTH (pg/mL) & $86.08 *$ & 34.09 & 0.001 \\
\hline
\end{tabular}

Bivariate correlations showed that ox-LDL was significantly associated with both nPCR and serum albumin $(\mathrm{r}=0.352, p=0.001$ and $\mathrm{r}=0.204, p=0.04$ respectively).

The enrolled subjects were divided in two groups according to the median value of ox-LDL/LDL-C equal with $88.8 \mathrm{ng} / \mathrm{mg}$ (inter-quartile range $58.3-161.7 \mathrm{ng} / \mathrm{mg}$ ).

Categorical associations showed significant relationship between high value of ox-LDL/LDL-C and systolic cardiac dysfunction $\left(x^{2}=7.6, p=0.005\right)$, although the association with coronary artery disease, diastolic dysfunction, left ventricular hypertrophy, hypertension and peripheral vascular disease, was found non-significant.

Secondarily, we divided our patients into two groups according to the cut-off point value of ox-LDL/LDL-C related to systolic cardiac dysfunction equal to $93.07 \mathrm{ng} / \mathrm{mg}$ defined by ROC curve analysis (Figure 1). $x^{2}$ tests showed significant association between high ox-LDL/LDL-C and systolic cardiac dysfunction $\left(x^{2}=9.04, p=0.003\right.$, Figure 2$)$, although the association with the other cardiovascular manifestations was found non-significant.

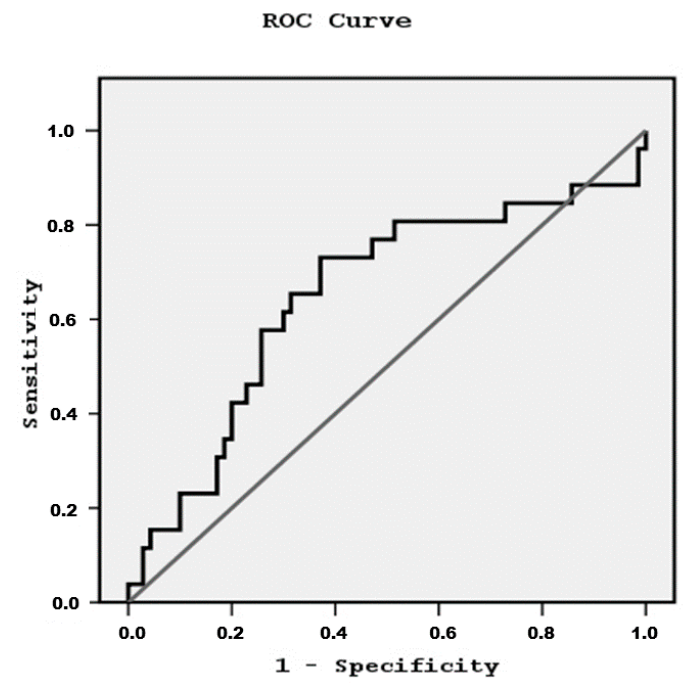

Figure 1. ROC curve showing the cut-off point of ox-LDL/LDL-C value related to systolic cardiac dysfunction equal to $93.07 \mathrm{ng} / \mathrm{mg}$ in enrolled subjects $(n=96)$. 
Bar Chart

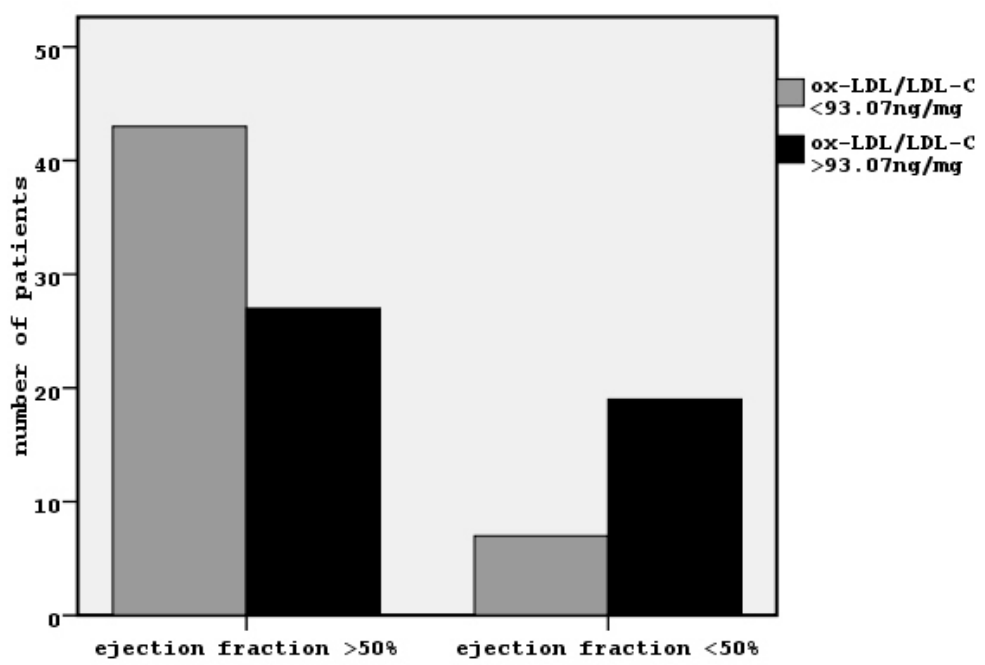

Figure 2. Bar Chart showing the relationship between systolic cardiac dysfunction, defined by ejection fraction less than $50 \%$ and the ratio of ox-LDL/LDL-C more or less than the cut-off point value equal to $93.07 \mathrm{ng} / \mathrm{mg}$ in our patients $(n=96)\left(\mathrm{x}^{2}=9.04, p=0.003\right)$.

In Table 2, the differences between the groups of patients with ejection fractions less or more than $50 \%$ are shown.

Table 2. Differences between groups of patients with and without systolic dysfunction, defined by ejection fraction less or more than $50 \%$ in a total of 96 hemodiafiltration patients $\left({ }^{*} p<0.05\right)$.

\begin{tabular}{|c|c|c|c|}
\hline Characteristic & $\begin{array}{c}\text { Patients with Ejection Fraction } \\
\text { Less Than } 50 \%(n=26) \\
\text { Mean } \pm \text { SD/Mean Rank }\end{array}$ & $\begin{array}{c}\text { Patients with Ejection Fraction } \\
\text { More Than } 50 \%(n=70) \\
\text { Mean } \pm \text { SD/Mean Rank }\end{array}$ & $p$ Value \\
\hline Age (years) & $68.8 \pm 12.6^{*}$ & $59.6 \pm 14.1$ & 0.005 \\
\hline Dialysis vintage (years) & 52.8 & 46.9 & 0.4 \\
\hline $\mathrm{spKt} / \mathrm{V}$ for urea & 46.1 & 49.4 & 0.6 \\
\hline $\mathrm{nPCR}(\mathrm{g} / \mathrm{Kg} /$ day $)$ & $2.2 \pm 0.6$ & $2.2 \pm 0.5$ & 0.9 \\
\hline Interdialytic urine volume (mL) & $225 \pm 154.1$ & $361.4 \pm 326.4$ & 0.3 \\
\hline Interdialytic weight gain (L) & $2.2 \pm 0.7$ & $2.3 \pm 1.1$ & 0.4 \\
\hline BMI $\left(\mathrm{Kg} / \mathrm{m}^{2}\right)$ & $24.8 \pm 3.3$ & $25.2 \pm 4.04$ & 0.7 \\
\hline $\mathrm{Hb}(\mathrm{gr} / \mathrm{dL})$ & $11.6 \pm 1.3$ & $11.9 \pm 1.4$ & 0.3 \\
\hline Cholesterol (mg/dL) & $158.5 \pm 47.3$ & $165.2 \pm 44.8$ & 0.5 \\
\hline $\mathrm{LDL}(\mathrm{mg} / \mathrm{dL})$ & $85.2 \pm 35.1$ & $92.5 \pm 37.8$ & 0.4 \\
\hline HDL (mg/dL) & $38.5 \pm 10.6$ & $39.02 \pm 9.4$ & 0.8 \\
\hline Triglycerides (mg/dL) & $181.7 \pm 111.6$ & $168.6 \pm 76.7$ & 0.6 \\
\hline oxLDL $(\mathrm{ng} / \mathrm{mL})$ & 55.9 & 45.7 & 0.1 \\
\hline OxLDL/LDL (ng/mg) & $58.9 *$ & 44.6 & 0.02 \\
\hline Albumin (gr/dL) & 43.8 & 50.2 & 0.3 \\
\hline Glucose (mg/dL) & $95.03 \pm 20.9$ & $96.6 \pm 22.9$ & 0.7 \\
\hline Insulin $(\mu \mathrm{U} / \mathrm{mL})$ & 44.7 & 49.9 & 0.4 \\
\hline HOMA-IR (mmol/L) & 44.9 & 49.8 & 0.5 \\
\hline $\mathrm{hsCRP}(\mathrm{mg} / \mathrm{L})$ & $12.06 \pm 5.4^{*}$ & $7.4 \pm 5.7$ & 0.001 \\
\hline $\mathrm{MCP}-1(\mathrm{pg} / \mathrm{mL})$ & 51.3 & 41.04 & 0.1 \\
\hline TNF- $\alpha(\mathrm{pg} / \mathrm{mL})$ & 50.06 & 44.3 & 0.3 \\
\hline i-PTH (pg/mL) & 47.3 & 48.9 & 0.8 \\
\hline $\mathrm{SBP}(\mathrm{mmHg})$ & $135.1 \pm 24.6$ & $130.4 \pm 23.5$ & 0.4 \\
\hline $\mathrm{MBP}(\mathrm{mmHg})$ & $99.4 \pm 14.8$ & $97.2 \pm 13.6$ & 0.5 \\
\hline c-fPWV $(\mathrm{m} / \mathrm{s})$ & $12.04 \pm 1.9^{*}$ & $11.02 \pm 1.7$ & 0.01 \\
\hline Augmentation index (Aix, \%) & $25.04 \pm 2.2$ & $23.8 \pm 2.3$ & 0.03 \\
\hline Pulse pressure (PP, mmHg) & $64.5 \pm 22.7 *$ & $54.4 \pm 19.1$ & 0.03 \\
\hline ABI & \pm 0.5 & \pm 0.4 & 0.4 \\
\hline $\mathrm{EF}(\%)$ & $25.8 \pm 2.7^{*}$ & $58.4 \pm 3.07$ & 0.001 \\
\hline $\mathrm{E} / \mathrm{A}$ ratio & 31.5 * & 54.8 & 0.001 \\
\hline $\begin{array}{l}\text { Thickness of interventricular } \\
\text { septum (mm) }\end{array}$ & $13.7 \pm 2.0$ * & $12.1 \pm 2.0$ & 0.001 \\
\hline
\end{tabular}


In the logistic regression analysis model built for the prediction of systolic cardiac dysfunction, high ox-LDL/LDL-C, old age and non-administration of vitamin D supplementation during dialysis sessions were found to be significant predictors after adjustment to confounders (Table 3). Moreover, the unadjusted association between systolic cardiac dysfunction and non-administration of vitamin $\mathrm{D}$ supplementation during dialysis sessions was found significant $\left(x^{2}=6.9, p=0.008\right)$.

Table 3. Logistic regression analysis for the prediction of systolic cardiac dysfunction using traditional and specific risk factors for hemodiafiltration patients.

\begin{tabular}{cccc}
\hline Characteristic & $p$-Value & Odds Ratio & Confidence Interval \\
\hline age & 0.01 & 1.06 & $1.01-1.11$ \\
gender & 0.8 & 1.1 & $0.3-3.8$ \\
Diabetes mellitus & 0.6 & 1.7 & $0.2-11.3$ \\
hypertension & 0.1 & 0.4 & $0.1-1.4$ \\
smoking & 0.4 & 1.9 & $0.4-8.6$ \\
spKt/V for urea & 0.9 & 0.9 & $0.2-4.5$ \\
nPCR & 0.2 & 0.5 & $0.2-1.5$ \\
Vitamin D therapy & 0.02 & 0.2 & $0.06-0.8$ \\
Ox-LDL/LDL-C & 0.004 & 6.2 & $1.8-21.2$ \\
\hline
\end{tabular}

The association between non-administration of vitamin D supplementation during dialysis session and high ox-LDL/LDL-C was found non-significant. However, the patients receiving vitamin D derivatives had significantly lower ox-LDL than and similar LDL-C serum levels to the patients without vitamin D therapy (mean-Rank 41.4 vs. $55.2, p=0.01$ and $92.1 \pm 31.2$ vs. $88.9 \pm 42.3, p=0.7$, respectively).

\section{Discussion}

In this study, we observed significant association between high ox-LDL corrected to LDL-cholesterol serum concentration and systolic cardiac dysfunction.

The patients in hemodialysis are highly subjected to increased oxidative stress and inflammation, either by their own characteristics, such as advanced age and high prevalence of diabetes mellitus, or by characteristics related to uremia and dialysis therapy, such as dialysis vintage, biocompatibility of dialysis membranes, exposure to endotoxins, parenteral administration of iron and the usage of erythropoiesis agents [13]. In this study, the participating patients were being treated using the same material dialysis membrane in every dialysis session, nobody had been treated by statin or parenteral administration of iron during the time period before study enrollment, and everybody was regularly receiving erythropoiesis agents in combination with orally receiving iron.

However, we observed elevated values of ox-LDL/LDL-C in our patients compared to healthy control subjects, who were matched for the age, gender and BMI. We also noted that the group of patients had significantly lower total cholesterol, HDL-C and albumin values as markers of nutritional status, although they had significantly higher triglycerides, hsCRP, i-PTH, insulin, insulin resistance, TNF-a, ox-LDL and mildly lower LDL-C in comparison with control group. The elevated markers of malnutrition in conjunction to inflammatory markers result in the co-occurrence of malnutrition, inflammation, and atherosclerosis (MIA syndrome) in dialysis patients, in agreement with the characteristics of our subjects, in spite of our exclusion criteria and the good status of our participants. Malnutrition has already been reported as a specific cardiovascular risk factor for this population of patients, and each of the MIA syndrome components worsens the survival of these patients [14]. Moreover, in this study we observed a significantly positive association between ox-LDL and both nPCR and serum albumin. By these findings, we could observe that the increased ox-LDL/LDL-C ratio in our patients comparative to control group was mainly based on high ox-LDL caused by oxidative state, and less on low LDL-C caused by malnutrition. We also could support that oxidative status in 
our data may be attributed to metabolic disorders due to uremia resulting in oxidative stress rather than to the conditions of hemodiafiltration therapy.

On the other hand, previously, it has been reported that oxidative stress is included into major determinants of metabolic disorders such as insulin resistance in hemodialysis patients, in combination with excess visceral fat and inflammation $[15,16]$. In this study, our patients had higher insulin and insulin resistance defined by HOMA-IR connected to higher ox-LDL than the healthy control group.

Oxidative stress can be defined as a tissue injury resulting from an imbalance between the generation of oxidizing components and insufficient production of antioxidant mechanisms [17]. Previously, it has been reported a significant correlation between oxidative stress markers, such as plasma glutathione, superoxide dismutase (SOD) and malonyldialdehyde (MDA) levels and cardiac dysfunction, including low ejection fraction in the end stage of renal disease [18]. Regarding the role of ox-LDL, it has been demonstrated that elevated levels of ox-LDL and ox-LDL autoantibodies in the plasma were associated with a lower ejection fraction in general population [19]. Moreover, a recent study showed increased ox-LDL levels in the left ventricle cavity, rather than in peripheral blood, suggesting an important contribution by localized ox-LDL formation in heart failure conditions [20].

In maintenance hemodialysis patients, previous reports showed no association between ox-LDL and major adverse cardiac events [21]. However, in chronic kidney disease patients, it has been suggested that ox-LDL may be a valuable marker of oxidative stress correlated with left ventricular hypertrophy [22]. In contrast, in this study, we did not observe such a significant association, although we noted significant association between high ox-LDL/LDL-C and low ejection fraction. These controversial findings may request bigger studies looking upon such an object.

Examining the groups of our subjects with and without low ejection fraction, we observed that those with low EF were elder and they had significantly elevated arterial stiffness markers, such as c-f PWV, Aix and PP, thickness of left ventricle wall and characteristic of diastolic dysfunction defined by low $\mathrm{E} / \mathrm{A}$ ratio in combination to higher ox-LDL, ox-LDL/LDL-C ratio and hsCRP than the patients with EF more than $50 \%$.

In combination with the important role of MIA syndrome, it has been established that arterial stiffness and vascular calcification are non-traditional cardiovascular risk factors in chronic kidney disease resulting in coronary arterial disease and heart failure [23]. Vascular calcification requires differentiation of vascular smooth muscle cells into osteoblast-like cells. This phenomenon can be activated by inflammatory cytokines and production of reactive oxygen species (ROS) [24]. The increased ROS generation during oxidative stress leads to more inflammation, since ROS are released from monocytes and polymorphonuclear cells with pro-inflammatory cytokines, which, in turn, amplify the generation of oxidants [25].

The presence of MIA syndrome related to arterial stiffness and vascular calcification may be included in pathophysiological mechanisms which outline the relationship between high ox-LDL and systolic cardiac dysfunction in this study. The built adjusted model also supported the importance of elevated ox-LDL in conjunction to aging and non-administration of vitamin D during dialysis session for the prediction of systolic dysfunction. Furthermore, we observed a significant unadjusted association between low ejection fraction and non-administration of vitamin D supplementation during dialysis sessions, and the subjects who were regularly receiving vitamin D derivatives had significantly lower ox-LDL than the patients who were not receiving vitamin D supplementation, although they had similar LDL-C.

In agreement, recently it has been reported that the usage of vitamin D derivatives in chronic kidney disease patients may prevent the elevated ROS production and the cytokine up-regulation by serum phosphate and may decrease the tissue factor expression in smooth muscle cells, resulting in beneficial cardiovascular effects $[26,27]$. 


\section{Conclusions}

This study showed a significant association between high ox-LDL and systolic cardiac dysfunction in permanent hemodiafiltration therapy patients. This relationship seems to be influenced by the aging and the pharmaceutical therapy during dialysis session including vitamin D derivatives.

\section{Limitations}

The important limitation of the study is its cross-sectional nature, which prevents the definition of the relationship between cause and effect in combination with the small number of included subjects. Also, the measurement of other markers of oxidative stress was unavailable.

Author Contributions: V.R.: research plan, statistics, data collection and manuscript writing; V.K.: hemodynamic measurements and Echo-cardiographical assessment; D.K.: biochemical analyses, ELISA and radioimmunoassays.

Funding: APC was sponsored by MDPI.

Conflicts of Interest: The authors declare no conflicts of interest.

\section{References}

1. Wen, C.P.; Cheng, T.Y.; Tsai, M.K.; Chang, Y.C.; Chan, H.T.; Tsai, S.P.; Chiang, P.H.; Hsu, C.C.; Sung, P.K.; Hsu, Y.H.; et al. All-cause mortality attributable to chronic kidney disease: A prospective cohort study based on 462293 adults in Taiwan. Lancet 2008, 28, 2173-2182. [CrossRef]

2. Inaba, M.; Ueda, M. Vascular Calcification-Pathological Mechanism and Clinical Application-The significance of arterial calcification in unstable plaques. Clin. Calcium 2015, 25, 679-686. [PubMed]

3. Go, A.S.; Chertow, G.M.; Fan, D.; McCulloch, C.E.; Hsu, C.Y. Chronic kidneydisease and the risks of death, cardiovascular events, and hospitalization. N. Engl. J. Med. 2004, 351, 1296-1305. [CrossRef] [PubMed]

4. Han, S.S.; Cho, G.Y.; Park, Y.S.; Baek, S.H.; Ahn, S.Y.; Kim, S.; Chin, H.J.; Chae, D.W.; Na, K.Y. Predictive value of echocardiographic parameters for clinical events in patients starting hemodialysis. J. Korean Med. Sci. 2015, 30, 44-53. [CrossRef] [PubMed]

5. Madamanchi, N.R.; Vendrov, A.; Runge, M.S. Oxidative stress and vascular disease. Arterioscler. Thromb. Vasc. Biol. 2005, 25, 29-38. [CrossRef] [PubMed]

6. George, J.; Wexler, D.; Roth, A.; Barak, T.; Sheps, D.; Keren, G. Usefulness of antioxidized LDL antibody determination for assessment of clinical control in subjects with heart failure. Eur. J. Heart Fail 2006, 8, 58-62. [CrossRef] [PubMed]

7. Vaziri, N.D. Oxidative stress in chronic renal failure: The nature, mechanism and consequences. Semin. Nephrol. 2004, 24, 469-473. [CrossRef] [PubMed]

8. Marsche, G.; Saemann, M.D.; Heinemann, A.; Holzer, M. Inflammation alters HDL composition and function: Implications for HDL-raising therapies. Pharmacol. Ther. 2013, 137, 341-351. [CrossRef] [PubMed]

9. Susantitaphong, P.; Siribamrungwong, M.; Jaber, B.L. Convective therapies versus low-flux hemodialysis for chronic kidney failure: A meta-analysis of randomized controlled trials. Nephrol. Dial. Transplant. 2013, 28, 2859-2874. [CrossRef] [PubMed]

10. Sternby, J.; Daugirdas, J.T. Theoretical basis for and improvement of Daugirdas' second generation formula for single-pool Kt/V. Int. J. Artif. Organs. 2015, 38, 632-637. [CrossRef] [PubMed]

11. Silva, E.A.; Flexa, F.; Zanella, M.T. Impact of abdominal fat and insulin resistance on arterial hypertension in non-obese women. Arq. Bras. Endocrinol. Metabol. 2009, 53, 340-343. [CrossRef] [PubMed]

12. Luman, M.; Jerotskaja, J.; Lauri, K.; Fridolin, I. Dialysis dose and nutrition assessment by optical on-line dialysis adequacy monitor. Clin. Nephrol. 2009, 72, 303-311. [CrossRef] [PubMed]

13. Nguyen-Khoa, T.; Massy, Z.A.; De Bandt, J.P.; Kebede, M.; Salama, L.; Lambrey, G.; Witko-Sarsat, V.; Drüeke, T.B.; Lacour, B.; Thévenin, M. Oxidative stress and haemodialysis: Role of inflammation and duration of dialysis treatment. Nephrol. Dial. Transplant. 2001, 16, 335-340. [CrossRef] [PubMed]

14. Jahromi, S.R.; Hosseini, S.; Razeghi, E.; Meysamie Ap Sadrzadeh, H. Malnutrition predicting factors in hemodialysis patients. Saudi J. Kidney Dis. Transplant. 2010, 21, 846-851.

15. Hung, A.M.; Ikizler, T.A. Factors determining insulin resistance in chronic hemodialysis patients. Contrib. Nephrol. 2011, 171, 127-134. [PubMed] 
16. Zanetti, M.; Barazzoni, R.; Guarnieri, G. Inflammation and insulin resistance in uremia. J. Ren. Nutr. 2008, 18, 70-75. [CrossRef] [PubMed]

17. Sies, H. Oxidative stress: Oxidants and antioxidants. Exp. Physiol. 1997, 82, 291-295. [CrossRef] [PubMed]

18. Al-Biltagi, M.; Tolba, O.A.; ElHafez, M.A.; Abo-Elezz, A.A.; El Kady, E.K.; Hazza, S.M. Oxidative stress and cardiac dysfunction in children with chronic renal failure on regular hemodialysis. Pediatr. Nephrol. 2016, 31, 1329-1339. [CrossRef] [PubMed]

19. Schimke, I.; Müller, J.; Dandel, M.; Gremmels, H.D.; Bayer, W.; Wallukat, B.; Wallukat, G.; Hetzer, R. Reduced oxidative stress in parallel to improved cardiac performance one year after selective removal of anti-beta 1-adrenoreceptor autoantibodies in patients with idiopathic dilated cardiomyopathy: Data of a preliminary study. J. Clin. Apher. 2005, 20, 137-142. [CrossRef] [PubMed]

20. Aluganti Narasimhulu, C.; Litvinov, D.; Sengupta, B.; Jones, D.; Sai-Sudhakar, C.; Firstenberg, M.; Sun, B.; Parthasarathy, S. Increased presence of oxidized low-density lipoprotein in the left ventricular blood of subjects with cardiovascular disease. Physiol. Rep. 2016, 4, e12726. [CrossRef] [PubMed]

21. Wagner, S.; Apetrii, M.; Massy, Z.A.; Kleber, M.E.; Delgado, G.E.; Scharnagel, H.; März, W.; Metzger, M.; Rossignol, P.; Jardine, A.; et al. Oxidized LDL, statin use, morbidity, and mortality in patients receiving maintenance hemodialysis. Free Radic. Res. 2017, 51, 14-23. [CrossRef] [PubMed]

22. Drożdż, D.; Kwinta, P.; Sztefko, K.; Kordon, Z.; Drożdż, T.; Łątka, M.; Miklaszewska, M.; Zachwieja, K.; Rudziński, A.; Pietrzyk, J.A. Oxidative Stress Biomarkers and Left Ventricular Hypertrophy in Children with Chronic Kidney Disease. Oxid. Med. Cell Longev. 2016, 2016, 7520231. [CrossRef] [PubMed]

23. Larivière, R.; Gauthier-Bastien, A.; Ung, R.V.; St-Hilaire, J.; Mac-Way, F.; Richard, D.E.; Agharazii, M. Endothelin type A receptor blockade reduces vascular calcification and inflammation in rats with chronic kidney disease. J. Hypertens. 2017, 35, 376-384. [CrossRef] [PubMed]

24. Agharazii, M.; St-Louis, R.; Gautier-Bastien, A.; Ung, R.V.; Mokas, S.; Larivière, R.; Richard, D.E. Inflammatory cytokines and reactive oxygen species as mediators of chronic kidney disease-related vascular calcification. Am. J. Hypertens. 2015, 28, 746-755. [CrossRef] [PubMed]

25. Descamps-Latscha, B.; Drüeke, T.; Witko-Sarsat, V. Dialysis-induced oxidative stress: Biological aspects, clinical consequences, and therapy. Semin. Dial. 2001, 14, 193-199. [CrossRef] [PubMed]

26. Martínez-Moreno, J.M.; Herencia, C.; de Oca, A.M.; Díaz-Tocados, J.M.; Vergara, N.; Gómez-Luna, M.J.; López-Argüello, S.D.; Camargo, A.; Peralbo-Santaella, E.; Rodríguez-Ortiz, M.E.; et al. High phosphate induces a pro-inflammatory response by vascular smooth muscle cells and modulation by vitamin D derivatives. Clin. Sci. 2017, 28, 1449-1463. [CrossRef] [PubMed]

27. Martinez-Moreno, J.M.; Herencia, C.; Montes de Oca, A.; Muñoz-Castañeda, J.R.; Rodríguez-Ortiz, M.E.; Díaz-Tocados, J.M.; Peralbo-Santaella, E.; Camargo, A.; Canalejo, A.; Canalejo, A.; et al. Vitamin D modulates tissue factor and protease-activated receptor 2 expression in vascular smooth muscle cells. FASEB J. 2016, 30, 1367-1376. [CrossRef] [PubMed]

(C) 2018 by the authors. Licensee MDPI, Basel, Switzerland. This article is an open access article distributed under the terms and conditions of the Creative Commons Attribution (CC BY) license (http://creativecommons.org/licenses/by/4.0/). 